\title{
Marked rebound thrombocytosis in response to glucocorticoids in a patient with acquired amegakaryocytic thrombocytopenia
}

\author{
Shogo Nishino, ${ }^{1)}$ Taiichi Kodaka, ${ }^{1)}$ Yoshie Sawada, ${ }^{1)}$ Takae Goka, ${ }^{2)}$ Yuta Gotoh, ${ }^{1)}$ \\ Hiroko Tsunemine, ${ }^{1)}$ Takayuki Takahashi ${ }^{1)}$
}

Acquired amegakaryocytic thrombocytopenia (AATP) is a rare disease characterized by thrombocytopenia and the disappearance of marrow megakaryocytes. A 43-year-old man was admitted because of thrombocytopenia of $1.0 \times 10^{9} / \mathrm{L}$. Bone marrow aspirate demonstrated normal hematopoiesis lacking megakaryocytes, and AATP was diagnosed. The serum concentration of thrombopoietin (TPO) was high $(7.72 \mathrm{fmol} / \mathrm{mL})$. Prednisolone (PSL) at $60 \mathrm{mg} /$ day was started and the platelet count recovered to $1,335 \times 10^{9} / \mathrm{L}$; however, excessive megakaryocytopoiesis and subsequent decline in platelet count were noted 14 days later. At the peak platelet count, the TPO remained at $3.79 \mathrm{fmol} / \mathrm{mL}$ and returned to a normal level of $0.40 \mathrm{fmol} / \mathrm{mL}$ during the period of normal platelet count after PSL tapering. The marked thrombocytosis in response to prednisolone may have been caused by the high TPO after the resolution of suppressed megakaryopoiesis. Marked rebound thrombocytosis beyond $1,000 \times 10^{9} / \mathrm{L}$ after successful PSL treatment for AATP has not been previously reported.

Keywords: acquired amegakaryocytic thrombocytopenia, glucocorticoid, thrombopoietin, rebound thrombocytosis

\section{INTRODUCTION}

Acquired amegakaryocytic thrombocytopenia (AATP) is a rare disease characterized by severe thrombocytopenia and the disappearance of megakaryocytes in the bone marrow, which consists of hematopoietic cells without dysplastic features. ${ }^{1}$ Immune mechanisms are considered to be involved in the thrombocytopenia and amegakaryocytic marrow. ${ }^{1}$ However, this disease is usually resistant to steroid therapy and many therapies have been employed with some success. ${ }^{1-26}$ We treated a patient with AATP who exhibited marked rebound thrombocytosis to more than $1,300 \times 10^{9} / \mathrm{L}$ in response to glucocorticoid therapy. Such marked rebound thrombocytosis has not been previously reported, and a high serum concentration of thrombopoietin (TPO) may have played a role in the high platelet count.

\section{CASE REPORT}

A 43-year-old man was referred to our hospital because of thrombocytopenia at the end of August 2017. At the beginning of the month, he had developed a sore throat without fever. He did not have any specific past or family history. Physically, neither purpura/petechiae of the extremities nor bleeding in the oral cavity was observed. Superficial lymph node swelling and hepatosplenomegaly were not noted. Laboratory examinations (Table 1) revealed a platelet count of $60 \times 10^{9} / \mathrm{L}$, a white blood cell count (WBC) of $9.2 \times 10^{9} / \mathrm{L}$ with $36.0 \%$ neutrophils, $12.0 \%$ monocytes, and $48.5 \%$ lymphocytes, and a hemoglobin concentration of 15.6 $\mathrm{g} / \mathrm{dL}$. An increased number of large granular lymphocytes was not noted. Monoclonal rearrangements of T-cell receptor- $\gamma$ and immunoglobulin heavy chain genes in circulating lymphocytes were not present, as examined by PCR (performed in July 2018) (data not shown). The serum concentration of platelet-associated $\operatorname{IgG}(\mathrm{PA}-\mathrm{IgG})$ was elevated to $64 \mathrm{ng} / 10^{7}$ cells (normally below $46 \mathrm{ng} / 10^{7}$ cells). Hemostatic tests, including PT, APTT, and fibrinogen, yielded normal results. Antibodies against Helicobacter pylori were not detected in the urine. Antinuclear factor was negative, and serum levels of complement ( $\mathrm{C} 3$ and $\mathrm{C} 4)$ were within normal limits. Based on these findings, a tentative diagnosis of immune thrombocytopenia (ITP) was made. One month later, the patient visited again with petechiae on the extremities.

\footnotetext{
Received: April 18, 2018. Revised: September 13, 2018. Accepted: September 18, 2018. J-STAGE Advance Published: November 9, 2018 DOI:10.3960/jslrt.18016

${ }^{1)}$ Departments of Hematology and ${ }^{2}$ Laboratory Medicine, Shinko Hospital, Kobe, Japan

Corresponding author: Takayuki Takahashi, Department of Hematology, Shinko Hospital, 4-47, Wakihama-cho, 1-chome, Chuo-ku, Kobe 651-0072, Japan. E-mail: takahashi. takayuki@shinkohp.or.jp

Copyright $(\subset) 2018$ The Japanese Society for Lymphoreticular Tissue Research

(c) BY-NC-SA This work is licensed under a Creative Commons Attribution-NonCommercial-ShareAlike 4.0 International License.
} 
Table 1. Laboratory findings on admission (August 2017)

\begin{tabular}{|c|c|c|c|c|c|}
\hline \multicolumn{2}{|l|}{ Hematology } & \multicolumn{2}{|c|}{ Chemistry } & \multicolumn{2}{|c|}{$\underline{\text { Serology }}$} \\
\hline WBC & $11.2 \times 10^{9} / \mathrm{L}$ & $\mathrm{TP}$ & $6.4 \mathrm{~g} / \mathrm{dL}$ & ANA & - \\
\hline $\mathrm{Neu}$ & $70.5 \%$ & Alb & $4.2 \mathrm{~g} / \mathrm{dL}$ & $\operatorname{IgA}$ & $168 \mathrm{mg} / \mathrm{dL}$ \\
\hline Eos & $0.0 \%$ & AST & $19 I U / L$ & $\operatorname{IgG}$ & $1,471 \mathrm{mg} / \mathrm{dL}$ \\
\hline Bas & $0.0 \%$ & ALT & 27IU/L & IgM & $42.0 \mathrm{mg} / \mathrm{dL}$ \\
\hline Mon & $9.0 \%$ & T-Bil & $0.9 \mathrm{mg} / \mathrm{dL}$ & $\mathrm{C} 3$ & $78.0 \mathrm{mg} / \mathrm{dL}$ \\
\hline Lym & $20.0 \%$ & D-Bil & $0.1 \mathrm{mg} / \mathrm{dL}$ & $\mathrm{C} 4$ & $25.8 \mathrm{mg} / \mathrm{dL}$ \\
\hline Aty-Lym & $0.5 \%$ & ALP & 147IU/L & & \\
\hline $\mathrm{RBC}$ & $453 \times 10^{10} / \mathrm{L}$ & LDH & $285 \mathrm{IU} / \mathrm{L}$ & \multicolumn{2}{|c|}{ (August $25^{\text {th }}$ ) } \\
\hline $\mathrm{Hb}$ & $14.0 \mathrm{~g} / \mathrm{dL}$ & $\gamma$-GTP & $37 I U / L$ & PAIgG & $64 \mathrm{ng} / 10^{7}$ cells \\
\hline $\mathrm{Ht}$ & $38.2 \%$ & BUN & $14.6 \mathrm{mg} / \mathrm{dL}$ & & \\
\hline Plt & $1.0 \times 10^{9} / \mathrm{L}$ & $\mathrm{Cr}$ & $1.00 \mathrm{mg} / \mathrm{dL}$ & \multicolumn{2}{|c|}{$\left(\right.$ October $\left.23^{\text {rd }}\right)$} \\
\hline Coagulation & & $\mathrm{Na}$ & $140 \mathrm{mEq} / \mathrm{L}$ & PAIgG & $3,300 \mathrm{ng} / 10^{7}$ cells \\
\hline PT-INR & 0.99 & $\mathrm{~K}$ & $3.7 \mathrm{mEq} / \mathrm{L}$ & & \\
\hline APTT & $27.1 \mathrm{~S}$ & $\mathrm{Cl}$ & $105 \mathrm{mEq} / \mathrm{L}$ & & \\
\hline Fib & $281 \mathrm{mg} / \mathrm{dL}$ & Glu & $98 \mathrm{mg} / \mathrm{dL}$ & & \\
\hline
\end{tabular}

Abbreviations: ANA: anti-nucleolar antibody, atyp.lym: atypical lymphocytes, PAIgG: platelet-associated IgG.

Normal range: C3 65-135 mg/dL, C4 13-35 mg/dL, PAIgG $<46 \mathrm{ng} / 107$ cells.

The platelet count had decreased to $4.0 \times 10^{9} / \mathrm{L}$; therefore, treatment with oral prednisolone (PSL: $20 \mathrm{mg} /$ day) was started. Three days later, his platelet count had further decreased to $1.0 \times 10^{9} / \mathrm{L}$, and he was admitted to our department. Bone marrow tap was performed after platelet transfusion. The marrow aspirate exhibited normocellular marrow lacking megakaryocytes $(0 / \mu \mathrm{L})$ (Figure 1A). No dysplastic features or an increase in the number of blasts was observed (Figure 1B). The aspirate was successfully obtained and we carefully observed the entire smear. Megakaryocytes were not observed in two smears and one particle smear preparation regardless of the reasonable numbers of granulocytes and erythrocyte precursors (Figure 1A). From these results, a diagnosis of AATP was made. Soon after the platelet transfusion, the platelet count increased to $33 \times 10^{9} / \mathrm{L}$, and then decreased to $29 \times 10^{9} / \mathrm{L}$ and $24 \times 10^{9} / \mathrm{L}$ on

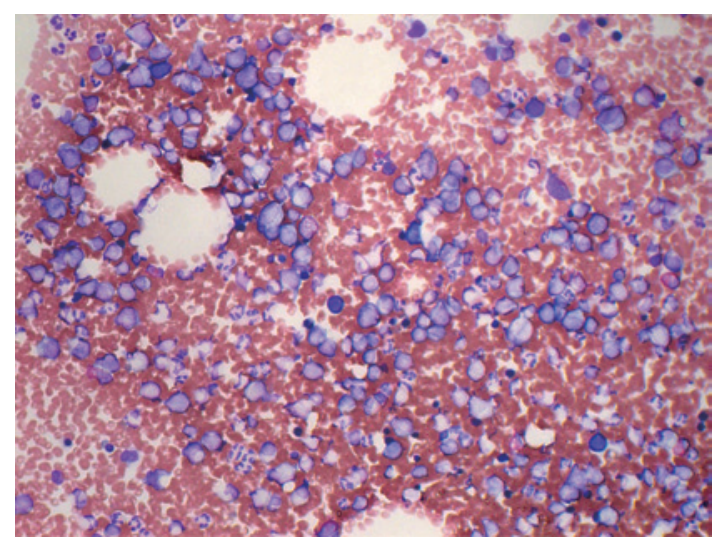

A days 1 and 3 after the transfusion, respectively. The dosage of PSL was increased to $60 \mathrm{mg} /$ day on day 1 after admission. In response to the increased dosage of PSL, the platelet count became elevated to $95 \times 10^{9} / \mathrm{L}$ and $1,335 \times 10^{9} / \mathrm{L}$ on days 7 and 14 , respectively. Therefore, the dosage of PSL was tapered with a gradual decrease in the platelet count to $858 \times 10^{9} / \mathrm{L}$ on day 26 , and the patient was discharged on the same day (Figure 2).

On day 10 , bone marrow re-examination was performed, revealing a marked increase in megakaryocytes $(312 / \mu \mathrm{L})$ (Figure 3). Of note, these megakaryocytes were mature but small to medium in size without dysplastic features or other lineage hematopoietic cells. The serum concentration of TPO on day 1 after admission was as high as $7.72 \mathrm{fmol} / \mathrm{mL}$ and slightly decreased to $3.79 \mathrm{fmol} / \mathrm{mL}$ on day 9 when the platelet count was $1,328 \times 10^{9} / \mathrm{L}$. Furthermore, the TPO

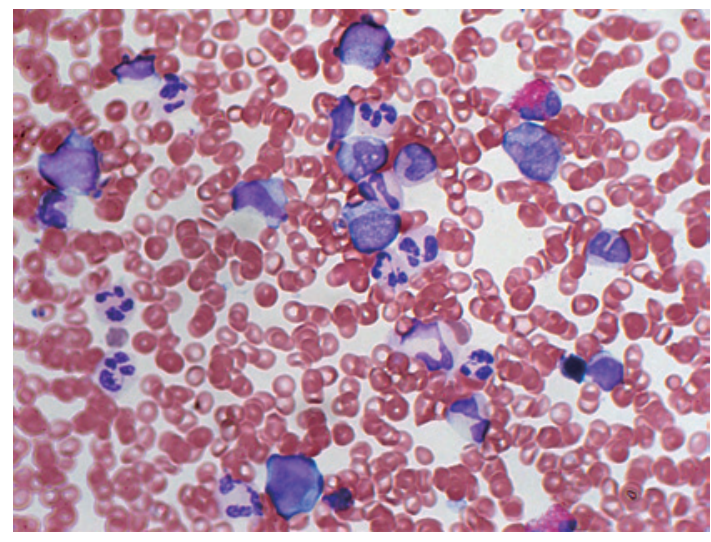

B

Fig. 1. Bone marrow images with particle and smear preparations at the diagnosis of AATP (October 24, 2017). A: A particle smear preparation of the marrow aspirate (Wright-Giemsa staining, $\times 200)$. The nucleated cell count was normal $\left(66.3 \times 10^{9} / \mathrm{L}\right)$ with a normal myeloid erythroid cell ratio (M/E ratio) and absence of megakaryocytes. $\boldsymbol{B}$ : A smear preparation of the same aspirate (Wright-Giemsa staining, $\times 400$ ). No dysplastic features or an increase in the number of blasts was observed. 


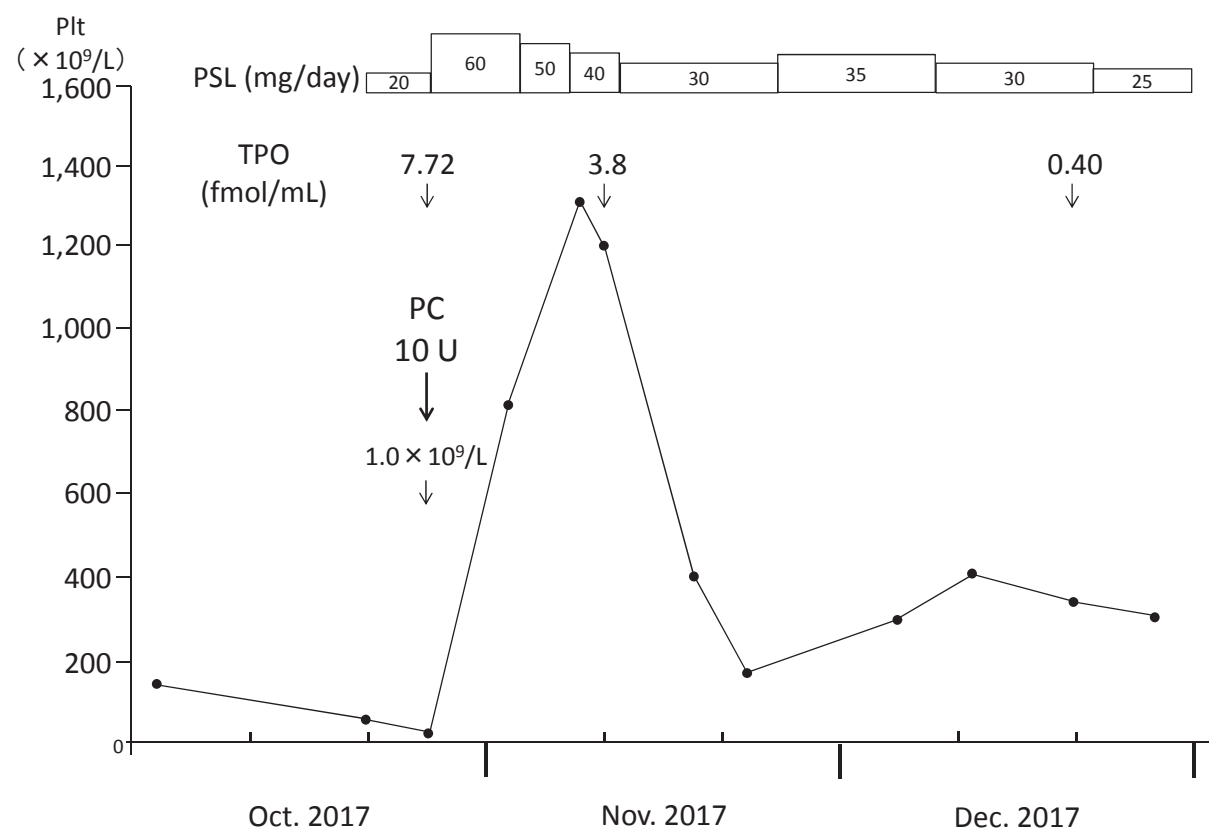

Fig. 2. Clinical course of the present patient. The platelet count markedly increased, with a peak count of $1,335 \times 10^{9} / \mathrm{L}$, after the initiation of glucocorticoid therapy, and gradually decreased as prednisolone was tapered. PSL: prednisolone, TPO: thrombopoietin.

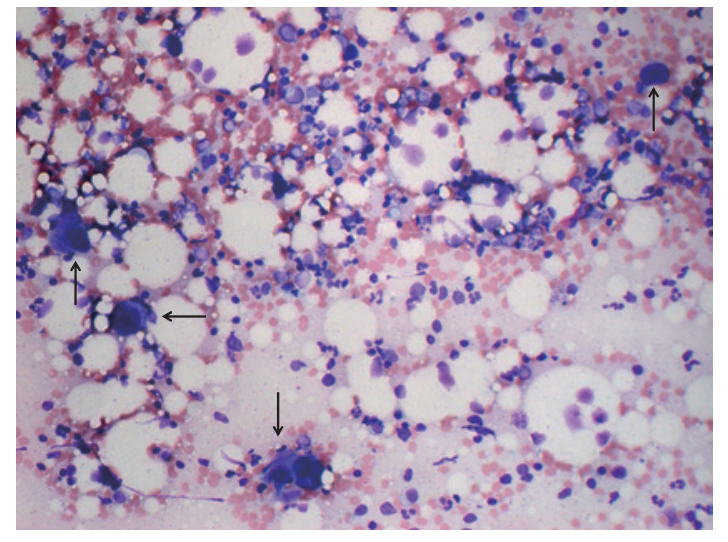

Fig. 3. A particle smear preparation of the bone marrow $(\times 200)$ at the peak platelet count after glucocorticoid therapy (November 9, 2017). The nucleated cell count was normal $\left(161.9 \times 10^{9} / \mathrm{L}\right)$, with a normal myeloid erythroid cell ratio $(\mathrm{M} / \mathrm{E}$ ratio) and increased number of mature megakaryocytes $(312 / \mu \mathrm{L})$. Megakaryocytes are mature, but most are medium in size (arrows).

concentration decreased to below $0.4 \mathrm{fmol} / \mathrm{mL}$, which was the normal level, at the outpatient department when the platelet count was $361 \times 10^{9} / \mathrm{L}$.

At the outpatient department, we tapered the dosage of PSL cautiously to prevent AATP relapse and secondary refractoriness of PSL to this disease because AATP is generally resistant to glucocorticoid therapy. During the tapering of PSL, the platelet count rapidly decreased from $418 \times 10^{9} / \mathrm{L}$ to $186 \times 10^{9} / \mathrm{L}$ with $30 \mathrm{mg}$ of PSL; therefore, the dosage of PSL was increased to $35 \mathrm{mg}$ /day with the recovery of platelet count at approximately $350 \times 10^{9} / \mathrm{L}$ (Figure 2 ). After this episode, PSL was tapered, and the platelet count has remained around $220 \times 10^{9} / \mathrm{L}$ with $7 \mathrm{mg}$ of PSL as of July 2018 .

\section{DISCUSSION}

AATP is a rare disease, and only 64 cases have been reported in the past 2 decades. ${ }^{1,5,6,12-16,21-23}$ In the present case, bone marrow examination should have performed when we made a tentative diagnosis of ITP because thrombocytopenic conditions include ITP, AATP, and other thrombocytopenic disorders. An autoimmune mechanism has been considered as the cause of AATP such as an antibody directed against $\mathrm{TPO}^{1}$ or c-Mpl, ${ }^{21,22,24}$ or cytotoxic immune cells against megakaryocyte precursors or progenitors. ${ }^{23,25,26}$ In support of an autoimmune mechanism, associations with other autoimmune diseases, such as systemic lupus erythematosus, ${ }^{21,24,25}$ rheumatoid arthritis, ${ }^{12}$ Sjögren's syndrome, ${ }^{18}$ and adult-onset Still's disease, ${ }^{7}$ have been reported. As another cause, the involvement of estrogen has been suggested. ${ }^{5}$ In the present patient, the presence of an antibody against c-Mpl or cytotoxic mechanism was suggested because the blood level of TPO was high. In AATP caused by a c-Mpl antibody, the response to glucocorticoid, rituximab, or bolus intravenous immunoglobulin (IVIg) therapy was delayed and insufficient in 3 reported cases. ${ }^{21,22,24}$ On the other hand, in AATP caused by a cytotoxic mechanism, the platelet recovery after glucocorticoid therapy was relatively rapid..$^{23,25,26}$ Therefore, in the present patient, some cytotoxic factor against megakaryocytes may have played a role. The upper respiratory symptom that preceded the onset of thrombocytopenia may have triggered the cytotoxic mechanism.

Regarding the mechanism of marked rebound thrombocytosis in the present patient, high blood TPO levels may have 
played an important role. Previously, high $(13.7 \pm 11.2 \mathrm{fmol} /$ $\mathrm{mL})$, mild $(1.25 \pm 0.39 \mathrm{fmol} / \mathrm{mL})$, and normal $(0.55 \pm 0.20$ $\mathrm{fmol} / \mathrm{mL}$ ) blood TPO levels have been reported in patients with AATP or ITP, and in healthy persons, respectively. ${ }^{27}$ The reason for the high TPO level in AATP has been explained by the sponge theory, proposing that megakaryocytes absorb blood TPO through c-Mpl, which they abundantly express. ${ }^{28}$ In accordance with this theory, the serum concentration of TPO was as high as $7.72 \mathrm{fmol} / \mathrm{mL}$ during the amegakaryocytic period in the present patient, and remained at $3.79 \mathrm{fmol} / \mathrm{mL}$ even in the recovery phase of thrombocytopenia. The marked rebound thrombocytosis may have been caused by the remaining TPO even after resolution of the immune-mediated suppression of megakaryopoiesis by glucocorticoid therapy. As for the remaining blood TPO during marked thrombocytosis, it may have taken time to sufficiently absorb blood TPO regardless of the increased number of marrow megakaryocytes. To the best of our knowledge, this role of TPO in the recovery phase of AATP and a high platelet count of more than $1,000 \times 10^{9} / \mathrm{L}$ after glucocorticoid therapy have not been previously reported.

As therapeutic strategies for AATP, glucocorticoid, ${ }^{1,3,4,7,7,10-12,22,23,25,26}$ high-dose IVIg, 1,7,8,22,23 anti-thymocyte globulin, ${ }^{4,9}$ cyclosporine A, ${ }^{7,9-12,23}$ rituximab, ${ }^{10,11}$ splenectomy, ${ }^{8}$ allogeneic hematopoietic stem cell transplantation, ${ }^{8}$ and agonists for c-Mpl,${ }^{10}$ androgens, ${ }^{5}$ and vincristine ${ }^{7,8}$ have been employed. Of these, glucocorticoid therapy, which is widely used and effective for ITP, is less effective for AATP. However, in the present patient, a rapid response to PSL was observed at $60 \mathrm{mg} / \mathrm{day}$, presumably due to a cytotoxic factor against megakaryocytes as stated above. Although low-dose PSL ( $7 \mathrm{mg} /$ day) should be sufficient to maintain remission, it may be challenging to maintain remission without glucocorticoids in the present patient.

In conclusion, we treated an AATP patient who exhibited marked rebound thrombocytosis after successful glucocorticoid therapy. High blood TPO levels may have led to the thrombocytosis.

\section{CONFLICT OF INTEREST}

The authors declare no conflict of interest in this study.

\section{REFERENCES}

1 Agarwal N, Spahr JE, Werner TL, Newton DL, Rodgers GM. Acquired amegakaryocytic thrombocytopenic purpura. Am J Hematol. 2006; 81 : 132-135.

2 Tristano AG. Acquired amegakaryocytic thrombocytopenic purpura: review of a not very well-defined disorder. Eur J Intern Med. 2005; $16: 477-481$.

3 Sakurai T, Kono I, Kabashima T, et al. Amegakaryocytic thrombocytopenia associated with systemic lupus erythematosus successfully treated by a high-dose prednisolone therapy. Jpn J Med. 1984; 23 : 135-138.

4 Manoharan A, Williams NT, Sparrow R. Acquired amegakaryo- cytic thrombocytopenia: report of a case and review of literature. Q J Med. 1989; $70:$ 243-252.

5 Kashyap R, Choudhry VP, Pati HP. Danazol therapy in cyclic acquired amegakaryocytic thrombocytopenic purpura: A case report. Am J Hematol. 1999; 60 : 225-228.

6 El Omri H, Skouri H, Kraiem I, et al. [Acquired amegakaryocytic thrombocytopenic purpura treated with intravenous immunoglobulins]. Ann Med Interne (Paris). 2000; 151 : 223-226 [in French with English abstract].

7 Her MY, Kim TH, Chang HK, Lee WS, Yoo DH. Successful treatment of acquired amegakaryocytic thrombocytopenia with cyclosporine in adult onset Still's disease. Rheumatol Int. 2007; $27: 295-298$

8 Lonial S, Bilodeau PA, Langston AA, et al. Acquired amegakaryocytic thrombocytopenia treated with allogeneic BMT: a case report and review of the literature. Bone Marrow Transplant. 1999; 24 : 1337-1341.

9 Brown GE, Babiker HM, Cantu CL, Yeager AM, Krishnadasan R. "Almost bleeding to death": the conundrum of acquired amegakaryocytic thrombocytopenia. Case Rep Hematol. 2014; $2014: 1-5$.

10 Cela I, Miller IJ, Katz RS, Rizman A, Shammo JM. Successful treatment of amegakaryocytic thrombocytopenia with eltrombopag in a patient with systemic lupus erythematosus (SLE). Clin Adv Hematol Oncol. 2010; 8 : 806-809.

11 Fukushima T, Dong L, Sakai T, et al. Successful treatment of amegakaryocytic thrombocytopenia with anti-CD20 antibody (rituximab) in a patient with systemic lupus erythematosus. Lupus. 2008; $17: 210-214$.

12 Hashimoto A, Kanisawa Y, Fujimi A, et al. Thrombocytopenia and anemia with anti-c-Mpl antibodies effectively treated with cyclosporine in a patient with rheumatoid arthritis and chronic renal failure. Intern Med. 2016; 55 : 683-687.

13 Ai DL, Li BT, Peng XM, et al. Acquired amegakaryocytic thrombocytopenic purpura induced by percutaneous ethanol injection during treatment of hepatocellular carcinoma: A case report. Oncol Lett. 2016; $11:$ 798-800.

14 Eddou H, Zinebi A, Khalloufi A, et al. [Acquired amegacaryocytic thrombocytopenic purpura hiding acute myeloid leukemia]. Pan Afr Med J. 2017; 26 : 32 [in French with English abstract].

15 Hashimoto A, Fujimi A, Kanisawa Y, et al. [Successful rituximab treatment for acquired amegakaryocytic thrombocytopenic purpura complicated with Coombs-negative autoimmune hemolytic anemia]. Rinsho Ketsueki. 2013; 54 : 568-573 [in Japanese with English abstract].

16 Niparuck P, Atichartakarn V, Chuncharunee S. Successful treatment of acquired amegakaryocytic thrombocytopenic purpura refractory to corticosteroids and intravenous immunoglobulin with antithymocyte globulin and cyclosporin. Int J Hematol. 2008; $88: 223-226$.

17 Zafar T, Yasin F, Anwar M, Saleem M. Acquired amegakaryocytic thrombocytopenic purpura (AATP): a hospital based study. J Pak Med Assoc. 1999; 49 : 114-117.

18 Ergas D, Tsimanis A, Shtalrid M, Duskin C, Berrebi A. T- $\gamma$ large granular lymphocyte leukemia associated with amegakaryocytic thrombocytopenic purpura, Sjögren's syndrome, and polyglan- 
dular autoimmune syndrome type II, with subsequent development of pure red cell aplasia. Am J Hematol. 2002; 69 : 132-134.

19 Maslovsky I, Gefel D, Uriev L, Ben Dor D, Lugassy G. Malignant thymoma complicated by amegakaryocytic thrombocytopenic purpura. Eur J Intern Med. 2005; 16 : 523-524.

20 Lu D, Chen Y, Ding R. [Study on the pathogenesis of acquired pure amegakaryocytic thrombocytopenic purpura]. Zhonghua Xue Ye Xue Za Zhi. 1999; 20 : 124-126 [in Chinese with English abstract].

21 Kuwana M, Okazaki Y, Kajihara M, et al. Autoantibody to c-Mpl (thrombopoietin receptor) in systemic lupus erythematosus: relationship to thrombocytopenia with megakaryocytic hypoplasia. Arthritis Rheum. 2002; $46: 2148-2159$.

22 Katsumata Y, Suzuki T, Kuwana M, et al. Anti-c-Mpl (thrombopoietin receptor) autoantibody-induced amegakaryocytic thrombocytopenia in a patient with systemic sclerosis. Arthritis Rheum. 2003; 48 : 1647-1651.

23 Lai DW, Loughran TP Jr, Maciejewski JP, et al. Acquired amegakaryocytic thrombocytopenia and pure red cell aplasia associated with an occult large granular lymphocyte leukemia. Leuk Res. 2008; 32 : 823-827.
24 Kuwana M, Kaburaki J, Okazaki Y, Miyazaki H, Ikeda Y. Two types of autoantibody-mediated thrombocytopenia in patients with systemic lupus erythematosus. Rheumatology. 2006; 45 : 851-854.

25 Nagasawa T, Sakurai T, Kashiwagi H, Abe T. Cell-mediated amegakaryocytic thrombocytopenia associated with systemic lupus erythematosus. Blood. 1986; 67 : 479-483.

26 Gewirtz AM, Sacchetti MK, Bien R, Barry WE. Cell-mediated suppression of megakaryocytopoiesis in acquired amegakaryocytic thrombocytopenic purpura. Blood. 1986; 68 : 619-626.

27 Mukai H, Kojima H, Todokoro K, et al. Serum thrombopoietin (TPO) levels in patients with amegakaryocytic thrombocytopenia are much higher than those with immune thrombocytopenic purpura. Thromb Haemost. 1996; 76 : 675-678.

28 Nagasawa T, Hasegawa Y, Shimizu S, et al. Serum thrombopoietin level is mainly regulated by megakaryocyte mass rather than platelet mass in human subjects. Br J Haematol. 1998; 101 : 242-244. 